\title{
Sustainable transport in cities: learning from best and worst practice?
}

\author{
A. Langeland \\ University of Stavanger, Norway
}

\begin{abstract}
It is generally recognized that a shift from car use to public transport, walking and cycling will reduce both local and global emissions. The goal of this paper was firstly to identify the European cities with the lowest and the highest car use, and secondly, to discuss if and how other cities can learn from the Best and Worst practice.

The top twenty of cycling cities in Europe is presented. Münster in Germany tops the list and is the European Bike City. The new TEMS EPOMM database makes it easy to compare a modal split in cities and thus answer questions like: Which city is most transport sustainable? Which city is the most car dependent? It is not surprising that they cycle a lot in Dutch cities, nor in Copenhagen, possibly more surprising that the bike is used extensively in Berlin? Milton Keynes has indeed become a car city, 75 percent of all trips is with a car. A line can be drawn through Europe. North of the line one find "cycling countries" and south of the line "car countries". Belgium is divided in two. Cities in the Flemish part to the north cycle a lot, while in Valona they hardly cycle. The paper discusses some of the findings and gives tentative answers to these differences between countries and cities.

Keywords: top sustainable transport cities, modal split, comparison of cities, learning from best and worst practice.
\end{abstract}

\section{Introduction}

The Climate Challenge has led to an active interest for sustainable urban transport, from the EU level, through states and down to municipalities and businesses. Integrated Land Use and Transport Planning seeks to intensify land use, prevent sprawl and shift people from cars to public transport, walking and 
cycling. "Cycling is good for you, your city and the environment" - the new mantra says. Many cities are therefore trying to achieve a shift from the car towards cycling, walking and public transport.

Some cities like Freiburg, Copenhagen and Amsterdam are presented as front runners in achieving the shift from car to more environmentally friendly modes. Cycling cities have become a hot topic in city marketing and very often one can find unreliable information as in Virgin Flight Magazine where Sandnes, Norway, was placed $7^{\text {th }}$ in the world, but in fact only $4 \%$ cycle. So what is the true picture of cycling in European cities?

This paper has used the TEMS EPOMM database to rank cities. Which is the World Bike City? Which Capital is best on cycling? Which city is most car dependent? The different rankings of the cities are discussed and some tentative answers to why countries and cities differ so much are given. The paper concludes that there is much to learn, but implementing other cities successes in another city is not straightforward.

\section{Method}

There are two major questions with comparison across borders. Firstly, to get a real understanding of what has been the major mechanisms that has produced a particular result in that particular context. Secondly, to transfer the understanding and lessons from one city to another must be difficult since very examples of such transfer of best practice exists. It may be that lessons from other places only can serve as inspiration for new policies because the contexts are different [1].

The comparisons of cities across country borders have been fraught with difficulties: lack of data, privately owned data, non-comparable data and not least, "political data" used for propaganda and as strategic misrepresentation. Strategic misrepresentation to support certain political goals, to "sell" the city, obtain money or favors from higher administrative levels, and/or obtain political goodwill is widespread, neither is deliberate lying to support a certain project or policy uncommon [2].

The recently established database TEMS a huge step forward. TEMS - The EPOMM Modal Split Tool, is a database that was made with the support of intelligent Energy Europe in the project EPOMM-Plus. There is still not a common standard or definition for: metropolitan area, urban area, city/ municipality/district area, they differ both in size and population according to source. Over time more data will be collected from more cities with more standardized survey methods and quality controls. TEMS is a splendid tool, which makes it possible to compare environmentally sustainable transport development in European cities and make inferences about countries.

\section{The top twenty cycling cities}

Figure 1 shows the top twenty bike cities in the world. Münster in Germany is the cycling city of the world with $38 \%$ of all trips on the bike. Four of the top cities have a cycling share over 30 percent. The data has come from the TEMS 
database, and the source for the population might differ from the mode split data. The table is limited to cities in which the car share is below $50 \%$. Seven of the twenty cities are German, five are Dutch, three Swedish and two from Denmark. One city is included in the table each from Italy, Switzerland and Belgium.

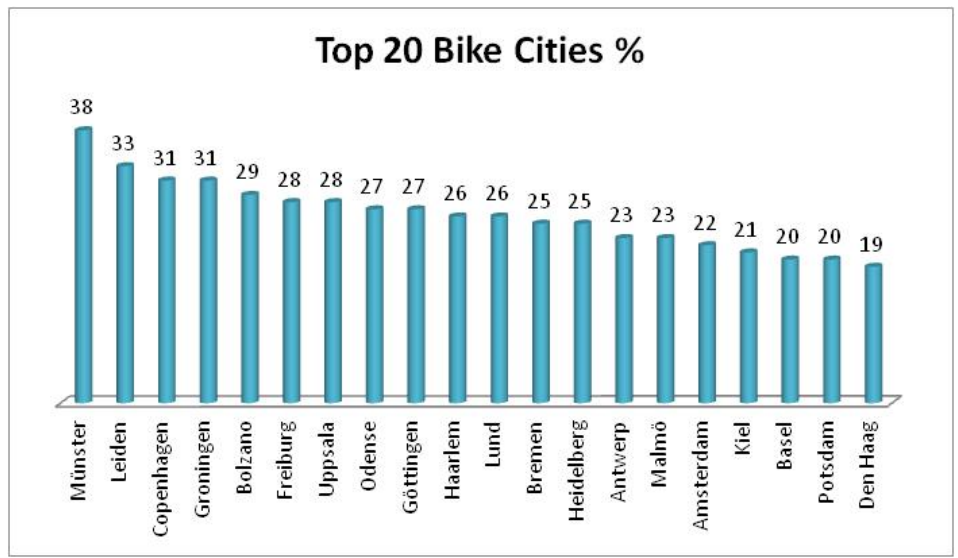

Figure 1: Top twenty bike cities.

The data can be sorted and looked at from different angles, for example top walking cities, top public transport cities, etc. The sum of walking and cycling is presented as top environmentally sustainable cities (as shown in Figure 2).

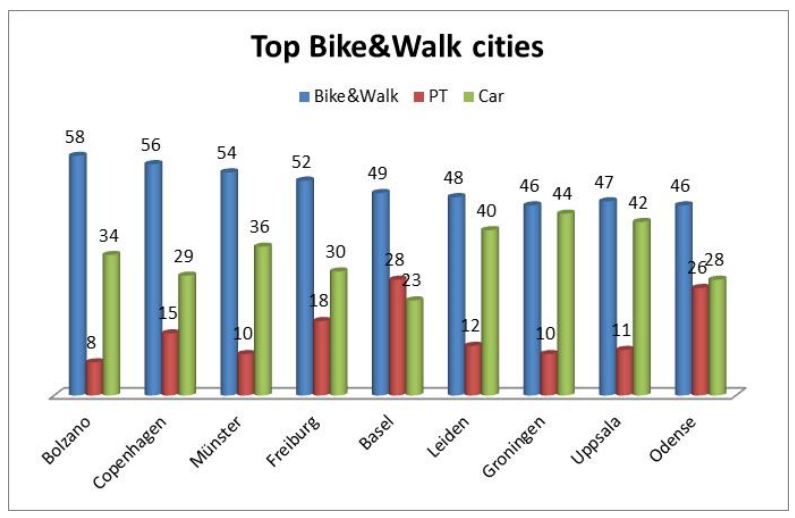

Figure 2: Top bike and walk cities.

Figure 2 shows a ranking according to the highest sum of walking and cycling. All cities have more than $45 \%$ bike/walk share. One should also look at low car use and then Basel comes out as best with only $23 \%$ car share. Bolzano the Italian city is very untypical of Italian cities coming to walking, cycling and bike use. They do cycle and walk a lot in Bolzano, as such the city resembles its neighbor to the north, Innsbruck, rather than other Italian cities. Why have no 
other Italian cities learnt from and replicated Bolzano's cycling success? What have been the barriers to do so?

\subsection{Münster: the world bike city}

The mode split development in Münster 1982-2007 is shown in the following figures. In 2001 there was a swing back to higher car share, which was reversed in 2007 . Hence, to maintain a level of cycling at $38 \%$ will require continual effort in the next years.

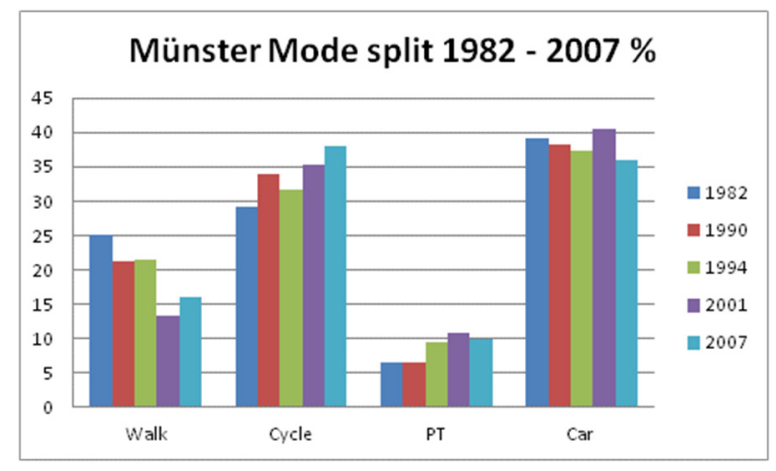

Figure 3: Münster mode split 1982-2007.

Münster is special when it comes to using the bicycle $-38 \%$ of all trips. It seems likely that the good cycle system attracts former car and public transport passengers and some who formerly walked. It may also be that the bike system generates its own traffic. When cycling increases in Münster, the walking decreases. Less than $40 \%$ car share is very good, but it raises the question if it is possible to decrease the car share much further in Münster? It might be that neither public transport nor cycling are alternatives to the car for many of the trips in the outer area of the city?

\subsection{The bad ones: the car "only" cities}

In the following table, the "bad cities" when it comes to car use are listed. The list is limited to three cities from each country. In the top ten of the worst car cities there are three cities from the UK, three from Belgium and three from France! Among the top twenty the Netherlands, Italy and Norway has three cities on the list. At the bottom of the list one finds the worst car city in Austria with only $49 \%$ car share, and the worst in Germany, Finland and Sweden with 57, 58 and 59 per cent respectively. Even better is the Swiss cities, all with car share less than $37 \%$. It is obvious that these countries control the use of the car in cities far better than those on the top of the list. 


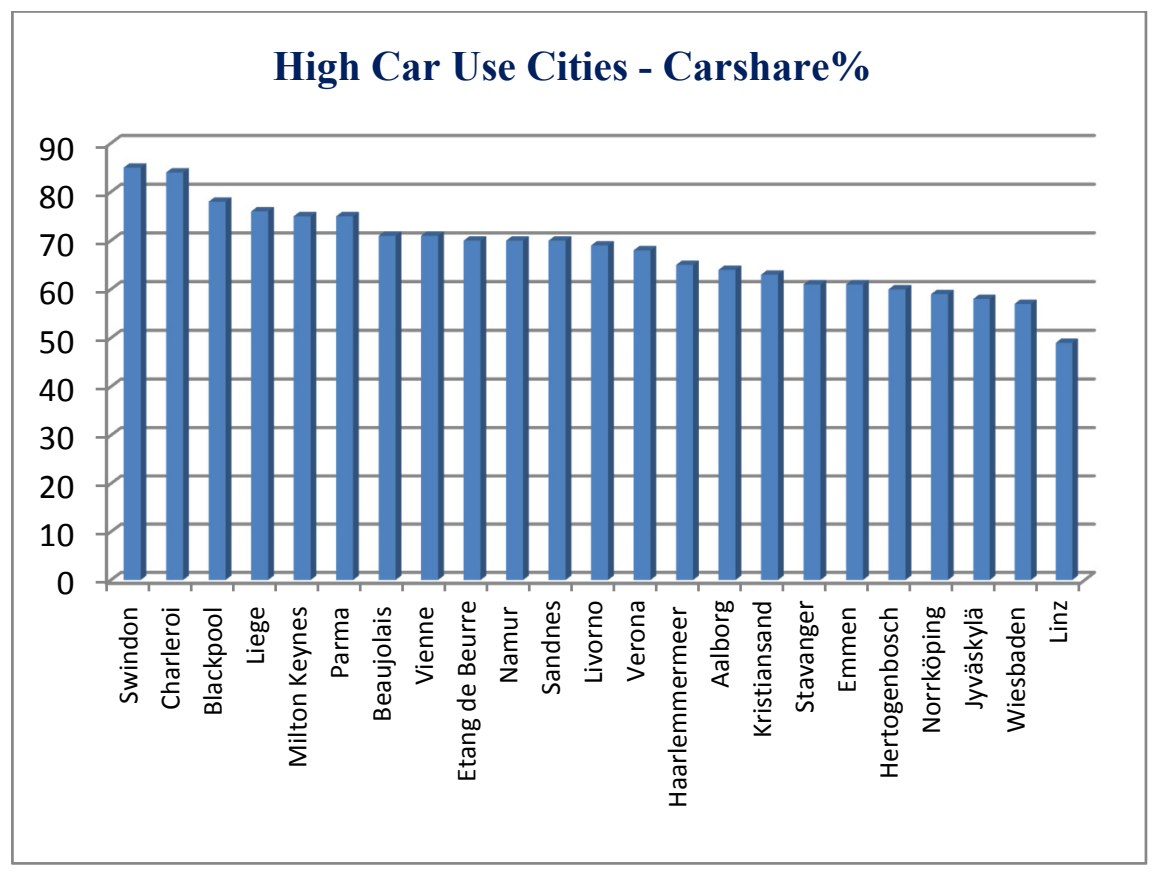

Figure 4: High care share cities.

\subsection{National differences}

There are striking differences between cities within nations and across national borders. There are some countries that hardly use the bike: Spain, France, Italy and UK, while others use the bike a lot. Netherlands, Denmark and Germany are the countries with several cities that are "bike cities". In Table 1 are listed the number of cities in each country with a bike share above $12 \%$ cycling.

Table 1: Nations with bike cities above $12 \%$.

\begin{tabular}{|l|l|}
\hline Country & Bike cities \\
\hline Netherlands & 26 cities \\
\hline Germany & 21 cities \\
\hline Sweden & 8 cities \\
\hline Finland & 5 cities \\
\hline Denmark & 4 cities \\
\hline Italy & 4 cities \\
\hline Austria & 3 cities \\
\hline Belgium & 3 cities \\
\hline Switzerland & 2 cities \\
\hline United Kingdom & 1 city \\
\hline
\end{tabular}




\subsubsection{Belgium}

Belgium is a special case. In the Flemish North, the cities of Brügge, Ghent and Antwerp are cycling cities with a high level of cycling resembling that in Dutch cities. In Valona to the south, hardly anyone cycle, just as in France further south, as shown on the following figure:

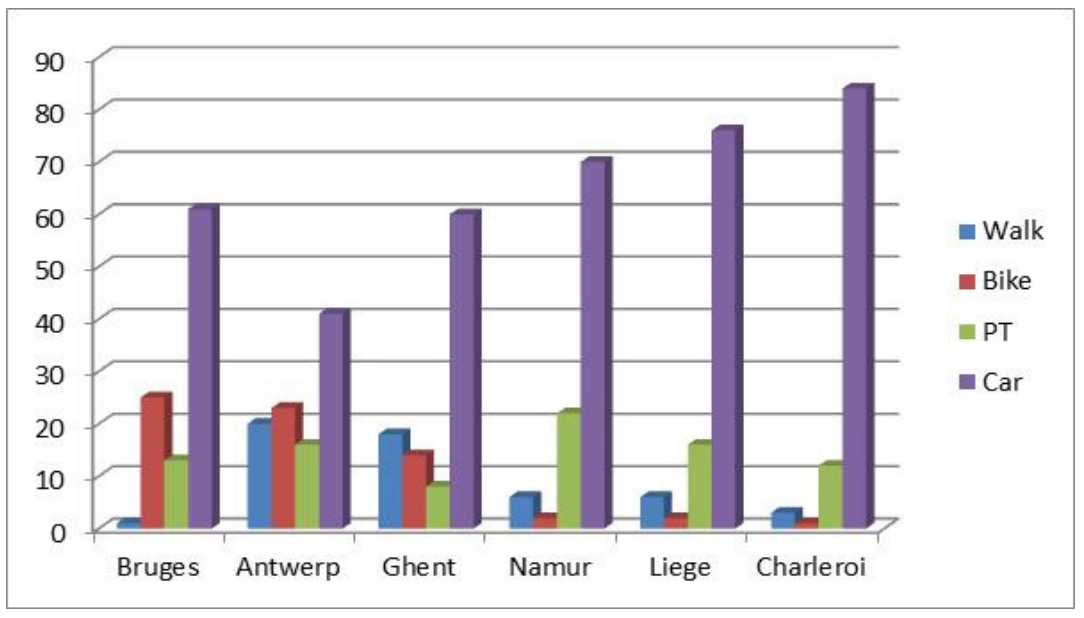

Figure 5: Belgian cities mode split.

\subsubsection{Great Britain}

Cycling does not have a large modal share in Great Britain. Only Bristol resembles European cycling cities. It is the very high car share that singles out Britain as being heavily car dependent. Newcastle has the lowest car share in Britain with only $30 \%$.

\section{Discussion}

\subsection{Does mode shift matter?}

Does it matter reducing car usage and transfering people from cars to public transport and bike and walking? The following calculation illustrates the effect of changing from the mode split similar to Milton Keynes to a mode split similar to Freiburg. The calculation is for work journeys only in an imaginary city with a population of about 250,000 inhabitants and about 100,000 workers that travel on average $11 \mathrm{~km}$ to work, 250 days every year.

The imaginary model city with Freiburg MS has yearly $\mathrm{CO}_{2}$ emissions of 156,000 tons, while with Milton Keynes MS the yearly $\mathrm{CO}_{2}$ emissions are 360,000 tons, which is 204,000 tons or 230 per cent more than in the Freiburg MS case. There are substantial gains in $\mathrm{CO}_{2}$ emissions with a transport policy that reduce car use in "car cities" and there are many such cities in Europe. 


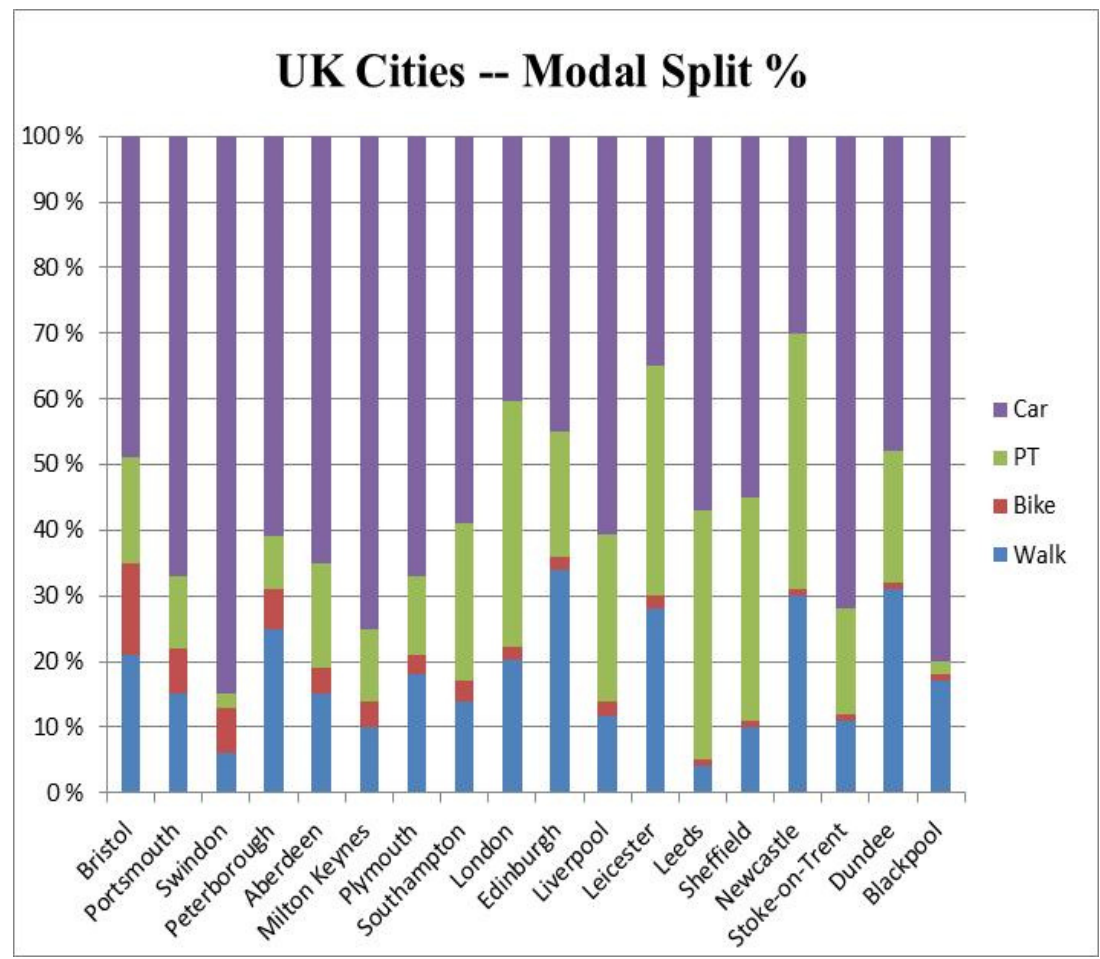

Figure 6: British cities mode split.

\subsection{Public attitude and image, history and culture}

In the fifties and sixties, some 25 years behind USA in car ownership, the vision of the car society swept through the planners minds in Europe. The car would solve the transport problems and there was no need for trams, bikes or buses in the vision of the future. The bike disappeared as a transport mode in the planner's minds and in practise, except in Holland, Germany and to a certain extent in Denmark. Milton Keynes, one of the English "new towns" is a prime example of how the planners' car vision was implemented. 75 percent of all trips in Milton Keynes are in a car. However, in many of the successful bike cities the planners' car modernisation ideas met opposition from the public.

This paper shows a marked cultural difference between the North Europe and the South. This divide is demonstrated in Belgium where bike use in Valona to the south is negligible while in the Flemish north bike use in the cities is very high and comparable to the Netherlands. What is it in the culture that can produce such different results? Can it be that the bicycle is looked upon as an intermediate technology and the car is the next and far superior technology? In England and Southern Europe they just skipped the bike and concentrated on acquiring the automobile? Such trends seem also to be present today in Eastern Europe. What then can explain the different development in Flanders and the 
Netherlands? In many of the present cycling cities it started with grass-root opposition to the car modernisation as in Amsterdam and Groningen in the sixties. The City of Davis in California for example, adopted a bike strategy in 1966, fought through by a couple returning from the Netherlands. Freiburg, which retained the tramway after strong public opposition to closing it down, became famous for developing "the environment card" a payment system for public transport. In the early nineties the design for the new urban area Vauban, became the example of how to design a sustainable city based on public transport as the main mode and with strong restrictions on cars [3].

The arrival of the mountain bike in the eighties suddenly changed the image of the bicycle from an outdated transport mode to an artefact for the hip professional for training as a supplement to "work outs" in the training studios. Thus the modern lifestyle mean cycling for pleasure/competition while the car is indispensable to sustain a "fast life". Amsterdam and Copenhagen certainly have a different attitude to bicycling. There it still is common to cycle to work for all income groups and in their ordinary clothes. There it is not necessary to behave as a MAMIL (middle-aged men in Lycra)!

\subsection{Income, car ownership and costs}

The cost, travel time door to door and the convenience of alternative modes have a crucial impact on modal choice [4]. With very fast growth in China, India and many more nations, the number of cars may reach 2 billion cars in a few decades [5]. Will these two billion cars leave place and space for the bicycle? Yes, the evidence in this paper shows that it is possible, especially in cities. There are many examples of cities with both a very wealthy population and a high level of bike use.

\subsection{Infrastructure, climate and safety}

Cities with high levels of bicycle use also have a good cycle network, but it is not clear if the infrastructure or the good network caused the amount of cyclists. The infrastructure may be a response to increased cycling instead of its cause. A network of separate bike paths and bike lanes as well as general streets with low speed seems to be necessary, but not a sufficient element in a Bike City.

Does climate matter? Cycling is obviously influenced by climate and topography, but there are questions to be raised. Why is cycling so prevalent in the wet Netherlands, while nearly non-existent in Southern France or Italy? Portland, which is both hilly and rainy, has the highest cycling rates in the USA [6]. Climate plays a role, but it is not the major barrier to increasing cycling.

"Cycling is dangerous" is often used to explain why many persons are not cycling. Colin Pooley, who led a major research project on sustainable travel, states: "It is essential that the urban environment is made safe for cyclists and pedestrians" [7]. It is therefore not likely to get $10-15 \%$ of the population to cycle regularly without a safe network. 


\subsection{More freedom to cities: less Government}

The main lesson from the successful bike cities is that at a certain point the car modernisation path was broken and shifted towards a bike path or a public transport path, or an eco-path, often a combination of all these. In many of the cities this was caused by successful Bottom-Up actions against proposed plans. Any strategy to increase walking and cycling should therefore be based on broad public participation. This is important not least because of the many societal barriers to increase cycling.

Another lesson from the successful bike cities is that they managed to make a coordinated action across all levels and layers, and developed a bike network. Far too often one finds that the governing structure and the incentives for the city planners and politicians work against sustainable transport in cities. The car infrastructure is expanded and the cost of using the car is going down, while the public transport suffers from decreasing quality and increased fares, and the cyclists are literally forced off the roads. In most Western European countries the nation state strongly steer the city transport system through the development of the infrastructure and the level of subsidies of the fares. Building bicycle networks in cities experience financial barriers. Who shall pay for the infrastructure? For roads the taxation of the car and petrol tax has paid for the roads, and many places toll roads are used to finance the infrastructure. Cyclists are however not a great source to be taxed to pay for the bike net. Establishing a separate bike net never has therefore not been in the forefront of the politicians' agenda. The successful bike cities have against the odds, managed to develop the cycling system. That this was possible is an important lesson to be learnt from the successful cities.

The shift away from the car modernisation path seems to have released creativity and innovation in the cities. It was very much a local focus that drove change. This underline that each city is unique and instruments and measures must be adapted to the local context. That what started as protest actions spread to become strategies and policies to improve the city environment, make them safer and more liveable.

\subsection{Learning from other cities?}

Allan Jones, who led the project turning Woking into a more sustainable city, claims that for a city to shift to a sustainability vision, three things are necessary:

- Political support;

- Chief officer support;

- Insider in the organization able and qualified to deliver the vision.

He continues: "- - this is not just about technology, it is also about politics and mindsets easily swayed by vested interests. Politics can be a very influential agent and lead the way in tackling climate change, but it can also be an agent for delay and procrastination in the fight to tackle climate change" [8].

Mode shift policies are deeply embedded in local context, the transport structure and the local culture. It is therefore not likely that learning from one city can be easily transferred to another. The successful sustainable cities have 
had hordes of delegations coming to learn and many papers are pointing to these successes. However, if one tries to find examples on how the learning has implemented in other cities, there are few if any to find. Freiburg and Groningen have had visits galore from foreign cities, and many planning documents advocate their solutions. Vauban in Freiburg has been the ideal model for how to plan a new neighborhood, but hardly implemented anywhere.

Several Norwegian cities have a 30 year history of broken promises, goals not achieved and plans not implemented. Kristiansand got a prize as Norway's leading bike city in 1983. The city is also twin city with Münster and every year delegations are visiting. However, Kristiansand has lost its position and only $9 \%$ use the bike at present. The goal of these two cities has been the same for 30 years. Kristiansand has failed to attain its goal, while Münster has implemented a successful bike strategy and become the world cycling city. It is not lack of knowledge that has hindered Kristiansand to reach its goals, but many other deterrents both physical and societal that has led to this result.

\section{Conclusions}

An intensive bicycle policy will not persist when it does not result in increased cycling, and a high degree of bicycle use will not persist if facilities are not upgraded and maintained [9]. TEMS with its present weaknesses has been used to make lists of best practices. The bicycling country is still the Netherlands, but the best cycling city is Münster in Germany with $38 \%$ of all trips on the bike. The German cities Freiburg and Münster are together with Bolzano, the top environmentally sustainable cities, while the Swiss cities are foremost on integrated transport planning, low car use and high use of public transport. Another lesson from Switzerland is wide public participation and the use of referendums to decide important planning issues.

Practice in one country might encourage innovation in another country, it is after all the main purpose of comparison. However, different planning traditions and political, institutional and cultural circumstances might require adaption to different environments. Thus, it might not be possible to transfer the practice from one country to another, as: "the danger of proposing change in practice in the light of experience abroad is that practice may be dependent for its success upon a chain of circumstances which does not apply at home" [10]. The ranking of cities presented in this paper can give insights and inspiration, hence go to Münster, to Bolzano, to Amsterdam, to Copenhagen and learn. Nevertheless, one should not only go to the best practice cities. There might be lessons that are more relevant from a city striving to reach its goals and not succeeding, as from the successful one.

\section{References}

[1] Booth, P., The design and implementation of cross-national research projects - introduction. Fischer, T.B. Strategic Environmental Assessment in Transport and Land Use Planning. Earthscan, 2002. 
[2] Flyvbjerg, B., Rationality and Power: Democracy in Practice. University of Chicago Press, 1998.

[3] Langeland, A., The Quest for Environmentally Sustainable Transport Development. Land use and transport planning in 4 cities in 4 countries. Aalborg University, 2009.

[4] Pucher, J., Buehler, R., \& Seinen, M., Bicycle renaissance in North America? An update and reappraisal of cycling trends and policies. Transportation Research Part A 45 451-475, 2011.

[5] Sperling, D., \& Gordon, D., Two Billion Cars. Oxford University Press, 2009.

[6] Pucher, J., Dill, J., \& Handy, S., Infrastructure, programs and policies to increase bicycling: an international review. Preventive Medicine, Volume 50, pp. 106-125, 2009.

[7] Pooley, C., Promoting walking and cycling. New perspectives on sustainable travel. Bristol, Policy Press, 2013.

[8] Jones, A., Moving Cities Towards a Sustainable Low Carbon Energy Future: Learning from Woking and London. In Davoudi, S. et al., eds. Planning for Climate Change. Strategies for mitigation and adaptation for spatial planners. Earthscan, London, 2009.

[9] Fietsberaad. Continuous and integral: The cycling policies of Groningen and other European cycling cities. Rotterdam: Fiestberaad. Publication no. 7, 2006.

[10] Hambleton, R. \& Thomas, H. Urban Policy Evaluation. Paul Chapman Publishing, London, 1995. 